\title{
Modelling batch drying of fine sand in a fountain confined conical spouted bed
}

\author{
Pablos, A. ${ }^{\text {a }}$ Tellabide, M.a ${ }^{a^{*}}$ Estiati, I. ${ }^{\text {; }}$ Vicente, J. ${ }^{\text {b }}$ Aguado, R. ${ }^{\text {a }}$ Olazar, M. ${ }^{\text {a }}$ \\ ${ }^{a}$ University of the Basque Country UPV/EHU, Spain \\ ${ }^{\mathrm{b}}$ Novattia Desarrollos Ltd., Spain \\ *E-mail of the corresponding author: mikel.tellabide@ehu.eus
}

\begin{abstract}
A rigorous model based on hydrodynamic considerations and mass and energy balances has been proposed for batch drying of fine sand in a fountain confined conical spouted bed. The results show that the proposed model predicts acceptably the evolution with time of moisture content in the solid and the final moisture content for the different operating conditions, with the mass transfer coefficient being the only adjustable parameter.
\end{abstract}

Keywords: Fine sand; spouted bed; batch drying; modelling. 


\section{Introduction}

Although numerous studies on drying have been reported in the literature concerning spouted beds, there are few ones approaching process modelling, which is due to the complexity involving the mathematical description of the phenomena occurring in the drying chamber, i.e., aspects involving thermodynamics, hydrodynamics, and heat and mass transfer. Therefore, the most common procedure is to perform approximations, which, depending on the rigor of the model, simplify the system behaviour in any of the mentioned aspects.

Most of the studies published are based on developing a macroscopic bed model that considers the mass and energy balances and the dynamics of the drying process. The drying mechanisms for the spout and annular zones are considered in these models. Becker and Sallans [1] made the first rigorous analysis of the continuous drying process of wheat in a conventional spouted bed, based on the assumption that bed height is enough to reach thermal equilibrium between exiting gas and the upper surface of the bed. In this way, diffusion of water from the solid inside to the surface limits the drying process. Later, Becker and Isaacson [2] and Viswanathan et al. [3] applied the same model to discontinuous drying, assuming an effective surface moisture content calculated from the dynamic equilibrium moisture content. The latter is obtained experimentally and, unfortunately, there is no data published in the literature. Chu and Hustrulid [4] demonstrated that even being convenient to assume that moisture content at the surface takes a constant value to facilitate calculation, computer problems are generated [2].

For discontinuous operation, Zuritz and Singh [5] proposed to calculate the moisture content on the surface by means of the variation of outlet air temperature and relative humidity. The authors tested an empirical equation that describes the desorption isotherms of equilibrium moisture. Later, Zahed and Epstein [6] deepened in this question using an empirical equation that relates the diffusion coefficient with temperature and solid moisture content. In addition, these authors propose that for continuous operation residence time distribution can be applied to the solids that make up the bed. With these two contributions, thermal equilibrium model with internal diffusion control has demonstrated its capacity to provide a good representation of wheat drying both for discontinuous and continuous operation.

Furthermore, Jumah et al. [7] developed a model for discontinuous corn drying using a novel jet spouted bed under constant and intermittent drying conditions. Unlike previous works, they do not assume thermal equilibrium at the end of the bed and also take into account temperature gradient within the bed. Kalwar and Raghavan [8] worked on drying of husked corn under minimum spouting velocity and found that there is no constant drying period. However, Wetchacama et al. [9] and Nguyen [10,11] found that moisture reduction rate remains constant. 
Madhiyanon et al. [12] proposed a batch drying model for vegetable grains. They assumed the process was neither in thermal equilibrium nor in isothermal regime, and it was validated with the experimental results for corn discontinuous drying in a two dimension spouted bed dryer. Unlike the previous studies, the modelling of spout and annular zones was made separately for a better description of drying thermodynamics. The model results agree with those predicted by grain circulation model, empirically formulated by Kalwar and Raghavan $[8]$.

Recently, Markowski et al. [13] published a study of drying dynamics of barley in a spouted bed and determined the influence of grain shape, which is considered in the model by the value of the effective diffusivity of moisture. Significant differences were observed when starting from an ellipsoidal or spherical geometry, so these results show that the proper definition of the solid geometry is essential for moisture diffusivity determination. They also demonstrated that assumption of spherical geometry is not a correct assumption when a great accuracy is desired in the predictions.

Although there is a relatively large amount of studies on drying in spouted beds, very few use conical spouted beds for drying solids [14-17]. Olazar et al. [18] proposed a model to predict the evolution of sand moisture in a conical spouted bed with nonporous draft tube. In this model, three regions (spout, annular zone and fountain) were considered and mass balances were described for water in solid and gaseous phases. The model was validated with experimental results. Based on these studies, this paper proposes a rigorous model for the batch drying in conical spouted beds, which is based on mass and energy balances and has only one adjustable parameter.

\section{Materials and Methods}

Drying of solids was carried out in a pilot plant consisting of a stainless steel conical vessel ( $1.62 \mathrm{~m}$ height, $\mathrm{D}_{\mathrm{c}}=0.36 \mathrm{~m}$ column diameter, $\mathrm{D}_{0}=0.05 \mathrm{~m}$ inlet diameter and $\gamma=32^{\circ}$ base angle) provided with an open-sided draft tube $\left(\mathrm{A}_{0} / \mathrm{A}_{\mathrm{T}}\right.$ ratio of $\left.60 \%\right)$ and a new fountain confinement device, which consists of a stainless steel pipe with the upper end closed. This device is under patent, and its dimensions are therefore confidential. Experiments were carried out at four temperatures $\left(30,50,100\right.$ and $\left.150{ }^{\circ} \mathrm{C}\right)$, three air velocities $\left(\mathrm{u} / \mathrm{u}_{0}=1.2,2\right.$ and 3$)$ and four wet sand pulses $(0.5,1,1.5$ and $2 \mathrm{~kg})$.

Modelling of drying is based on the assumption that the spouted bed behaves like a perfect mixing ideal vessel. Therefore, it is considered that all particles have the same moisture content and temperature at any time, and also that air humidity and temperature is the same at the drying chamber and the outlet. In addition, the model considers the humidity content of the gas at the inlet and exit, and the fact that the solid remains in the bed during the run. 
The procedure for the simulation is similar to that followed in the experimentation. A bed of dry sand is being spouted at a temperature corresponding to the outlet gas and a given mass of wet sand $\left(\mathrm{x}_{\mathrm{so}}=15 \% \mathrm{w} / \mathrm{w}\right)$ is added at $\mathrm{t}=0$ as a pulse injection.

Based on these assumptions, the following mass and energy balances are considered: 1) Water mass balance for the wet sand added, 2) water mass balance for the gas phase, 3) energy balance for the wet sand added, 4) energy balance for dry sand (initial bed) and 5) energy balance for the gas phase, which should take into account heat losses from the drying chamber to the atmosphere.

Given that the experimental study showed that both gas and solid temperatures do not remain constant during the process, air, liquid water and steam properties are calculated at the corresponding temperature at each time and position. This includes air viscosity and density ( $\mu$ and $\rho_{\mathrm{g}}$, respectively), water vapor pressure $\left(\mathrm{P}_{\mathrm{vw}}\right)$, diffusivity of water into air $\left(\mathrm{D}_{\mathrm{AB}}\right)$, volumetric gas flow and velocity $(\mathrm{u})$, mass transfer coefficient $(\mathrm{K})$, heat capacity of water, steam and air $\left(\mathrm{C}_{\mathrm{pw}}, \mathrm{C}_{\mathrm{pv}}\right.$ and $\mathrm{C}_{\mathrm{pg}}$, respectively), thermal conductivity of the air $(\mathrm{kg})$, heat transfer coefficient of the gas $(\mathrm{h})$ and latent heat of water vaporization $(\lambda)$.

Drying rate, $R_{w}$, is defined as:

$$
R_{W}=K a\left(y_{s a t}-y_{g}\right)\left|\rho_{g}\right|_{T_{g}}
$$

where $\mathrm{K}$ is the mass transfer coefficient, a the gas-solid interface area or wet area, $\mathrm{y}_{\text {sat }}$ the equilibrium moisture at the gas-liquid interface (or saturation humidity), $\mathrm{yg}_{\mathrm{g}}$ the gas moisture in the drying chamber (and at the exit) and $\left|\rho_{\mathrm{g}}\right|_{\mathrm{To}}$ the density of the gas at the inlet temperature.

The gas-liquid interface area or wet area, a, depends on the moisture content of the particle. When moisture content of sand is high, the water covers the entire surface of the particle and, as explained above, $R_{w}$ is constant. When humidity drops to the value corresponding to the critical humidity, $\mathrm{x}_{\mathrm{s}, \mathrm{c}}$, the water cannot cover the entire surface of the particle, and therefore the interface area causes a gradual decrease in the drying rate. These two stages are described by Eq. 2 and 3:

$$
\begin{gathered}
x_{s}>x_{s, c} \rightarrow a=A \\
x_{s} \leq x_{s, c} \rightarrow a=A \frac{x_{s}}{x_{s, c}}
\end{gathered}
$$

In addition, runs have been carried out assuming a time depending exchange area, even during the drying step at constant rate. This assumption is based on the fact that sand agglomerates are formed at the beginning, but their diameter decrease during the drying process, and therefore the mass transfer surface increases. Accordingly, in addition to Eqs. 2 and 3, various mathematical functions have been tested to monitor this surface change over time (straight line, vertical parabola, hyperbolic tangent and exponential). 
The critical humidity point, $\mathrm{x}_{\mathrm{s}, \mathrm{c}}$, is determined based on the experimental results. The equilibrium moisture at the gas-liquid interface, $\mathrm{y}_{\mathrm{sat}}$, expressed as a percentage by weight on a dry basis, is calculated from the vapour pressure of the water at the temperature of the solid.

\section{Results and discussion}

Once the value of best fit has been determined for the single adjustable parameter (mass transfer coefficient, K) the model suitably predicts the reduction in sand moisture content, as shown in the parity plot in Fig. 1, in which the experimental values of $\mathrm{x}_{\mathrm{c}}$ have been plotted versus the calculated ones. As observed, the model underestimates the drying rate in the first half of the drying period (for high values of $\mathrm{x}_{\mathrm{s}}$ ), whereas in the second half (low values of $\mathrm{x}_{\mathrm{s}}$ ) the model predicts a faster drying than that measured experimentally.

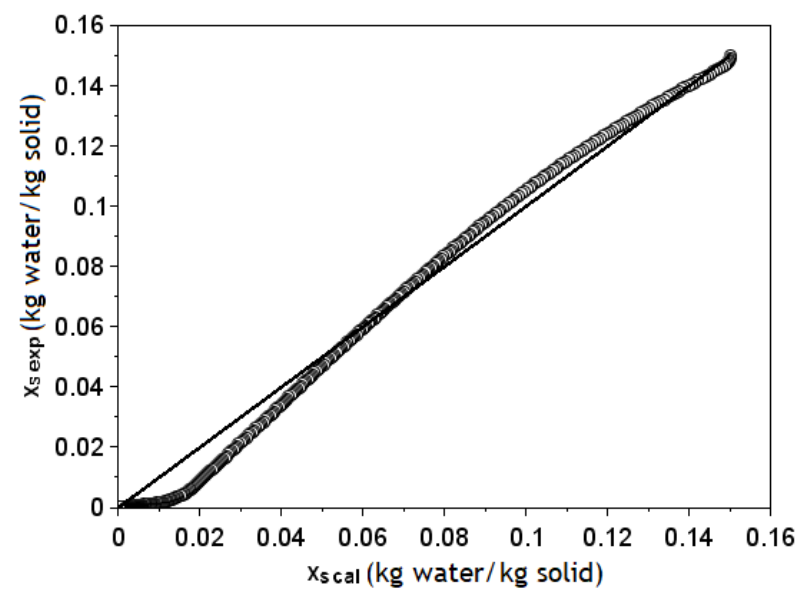

Fig. 1 Experimental and calculated values of water content in the added sand.

Fig. 2 shows the evolution with time of the experimental and calculated values of bed moisture content, $\mathrm{x}_{\mathrm{s}}$, and the absolute humidity of the air at the outlet gas, $\mathrm{y}_{\mathrm{g}}$. It is observed that calculated values of $x_{s}$ are very close to the experimental ones, but there is a considerable difference between calculated and experimental values of $y_{\mathrm{g}}$. The model is not able to predict the typical curve in drying processes, in which humidity peaks at a very short time, it then decreases smoothly until a constant value is reached, and finally undergoes a sharp decrease to reach the critical moisture content. The calculated values show an evolution without the initial peak, and the absolute humidity of the air remains approximately constant with a higher value than the experimental one. 


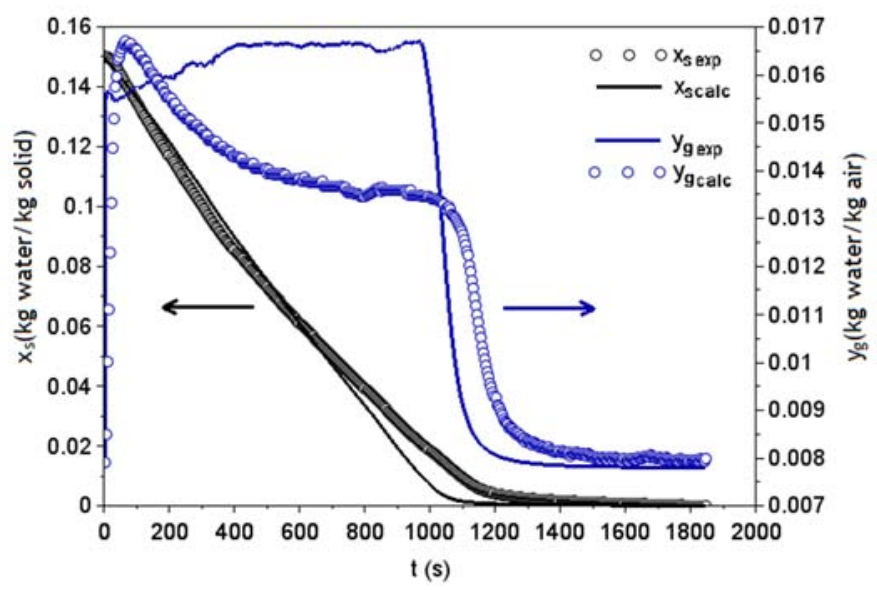

Fig. 2 Evolution with time of the solid moisture content and the air absolute humidity. Points, experimental values, lines, calculated with the proposed model.

To correct these differences, the heat transfer estimation should be improved in the model, since the predictions of the outlet gas temperature by the model do not match the experimental results, and this fact has a great impact on the value of $y_{g}$. Accordingly, we are at present involved in the analysis of several options for the estimation of the parameters involving heat transfer, such as the heat transfer coefficients in the bed and those related to heat losses.

\section{Conclusions}

The proposed model predicts acceptably the evolution with time of moisture content in the solid and the final moisture for the different operating conditions, with the mass transfer coefficient being the only adjustable parameter.

The model underestimates the drying rate in the first half of the process, whereas overestimates in the second half. In order to overcome these shortcomings, heat transfer description should be improved by means of a more detailed definition of convective coefficients and global transfer coefficients for heat loss.

\section{Nomenclature}

$\begin{array}{lll}\text { a } & \text { Gas-liquid interface area } & \mathrm{m}^{2} \mathrm{~kg}^{-1} \\ \text { A } & \text { Surface area of the solid } & \mathrm{m}^{2} \mathrm{~kg}^{-1} \\ \mathrm{x}_{\mathrm{s}} & \begin{array}{l}\text { Moisture content by solid mass } \\ \text { unit }\end{array}\end{array}$




$\begin{array}{ll}\mathrm{x}_{\mathrm{s} 0} & \begin{array}{l}\text { Initial moisture content by } \\ \text { solid mass unit }\end{array} \\ \mathrm{x}_{\mathrm{s}, \mathrm{c}} & \begin{array}{l}\text { Critical moisture content by - } \\ \text { solid mass unit }\end{array} \\ \mathrm{y}_{\mathrm{g}} & \begin{array}{l}\text { Moisture content by air mass } \\ \text { unit }\end{array}\end{array}$

\section{Acknowledgements}

This work has been carried out with the financial support from the Ministry of Economy and Competitiveness of the Spanish Government (CTQ2016-75535-R (AEI/FEDER, UE)), the University of the Basque Country UPV/EHU (US14/37) and the collaboration of Novattia Desarrollos Ltd. Aitor Pablos and M. Tellabide thank The University of the Basque Country (UPV/EHU) and the Ministry of Education, Culture and Sport (FPU14/05814), respectively, for their Ph.D. grants

\section{References}

[1] H. A. Becker y H. R. Sallans, «Drying wheat in a spouted bed. On the continuous, moisture diffusion controlled drying of solid particles in a well-mixed, isothermal bed», Chemical Engineering Science, vol. 13, n. ${ }^{\circ}$ 3, pp. 97-112, 1961.

[2] H. A. Becker y R. A. Isaacson, «Wheat drying in well-stirred-batch and continuousmoving-bed dryers», Can. J. Chem. Eng., vol. 48, n. ${ }^{\circ}$ 5, pp. 560-567, oct. 1970.

[3] K. Viswanathan, M. S. Lyall, K. S. Negi, y B. C. Raychaudhury, «Experimental and theoretical study of batch drying of whaeat in spouted beds.», 1984, pp. 552-558, pn.

[4] Shu-Tung Chu and Andrew Hustrulid, "General Characteristics of Variable Diffusivity Process and the Dynamic Equilibrium Moisture Content», vol. 11, n. ${ }^{\circ}$ 5, 1968.

[5] C. A. Zuritz y R. P. Singh, «Simulation of rough rice drying in a spouted bed», Paper - American Society of Agricultural Engineers, 1980.

[6] A. H. Zahed y N. Epstein, «Batch and continuous spouted bed drying of cereal grains: The thermal equilibrium model», Can. J. Chem. Eng., vol. 70, n. ${ }^{\circ}$ 5, pp. 945-953, oct. 1992.

[7] R. Y. Jumah, A. S. Mujumdar, y G. S. V. Raghavan, «Batch Drying Kinetics of Cornin a Novel Rotating Jet Spouted bed», Canadian Journal of Chemical Engineering, vol. 74, pp. 479-486, 1996.

[8] M. I. Kalwar y G. S. V. Raghavan, «Batch Drying of Shelled Corn in TwoDimensional Spouted Beds with Draft Plates», Drying Technology, vol. 11, n. ${ }^{\circ}$ 2, pp. 339-354, ene. 1993.

[9] S. Wetchacama, S. Soponronnarit, T. Swasdisevi, J. Panich-ich-orn, y S. Suthicharoenpanich, «Drying of High Moisture Paddy by Two-Dimensional Spouted Bed Technique», en Proceedings of the First Asian-Australian Drying Conference (ADC’99), Bali, Indonesia, 1999, pp. 300-307.

[10] L. H. Nguyen, «Evaluation of a Modified Spouted Bed Dryer for High Moisture Grain Drying. Tesis para la University of New South Wales.», PhD Tesis, University of New South Wales, Australia, 2000. 
[11] L. Hung-Nguyen, R. H. Driscoll, y G. Srzednicki, «Modeling the drying process of paddy in a triangular spouted bed», en Proceedings of the 12th International Drying Symposium, IDS2000, Amsterdam, 2000, vol. 269.

[12] T. Madhiyanon, S. Soponronnarit, y W. Tia, «Industrial-Scale Prototype of Continuous Spouted Bed Paddy Dryer», Drying Technology, vol. 19, n. ${ }^{\circ}$ 1, pp. 207-216, ene. 2001.

[13] M. Markowski, I. Białobrzewski, y A. Modrzewska, «Kinetics of spouted-bed drying of barley: Diffusivities for sphere and ellipsoid», Journal of Food Engineering, vol. 96, n. ${ }^{\circ}$ 3, pp. 380-387, feb. 2010.

[14] J. Costa, F. B. Freire, J. T. Freire, y M. L. Passos, «Spouted beds of inert particles for drying suspension», Drying Technology, vol. 24, n. ${ }^{\circ}$ 3, pp. 315-325, 2006.

[15] M. L. Passos, G. Massarani, J. T. Freire, y A. S. Mujumdar, «Drying of pastes in spouted beds of inert particles: Design criteria and modeling», Drying Technology, vol. 15, n. ${ }^{\circ}$ 2, pp. 605-624, 1997.

[16] H. Altzibar, G. Lopez, S. Alvarez, M. J. San Jose, A. Barona, y M. Olazar, «A drafttube conical spouted bed for drying fine particles», Drying Technology, vol. 26, n. ${ }^{\circ} 3$, pp. 308-314, 2008.

[17] L. Spreutels, B. Haut, J. Chaouki, F. Bertrand, y R. Legros, «Conical spouted bed drying of Baker's yeast: Experimentation and multi-modeling», Food Research International, vol. 62, pp. 137-150, abuztua 2014.

[18] M. Olazar, G. Lopez, H. Altzibar, A. Barona, y J. Bilbao, «One-dimensional modelling of conical spouted beds», Chemical Engineering and Processing, vol. 48, n. ${ }^{\circ}$ 7, pp. 1264-1269, jul. 2009.

[19] B. Thorley, K. B. Mathur, J. Klassen, y P. E. Gishler, «Effect of Design Variables on Flow Characteristics in a Spouted Bed», National Research Council of Canada, 1958.

[20] W. Du, W. Wei, J. Xu, Y. Fan, y X. Bao, «Computational fluid dynamics (CFD) modeling of fine particle spouting», International Journal of Chemical Reactor Engineering, vol. 4, sep. 2006.

[21] C. J. Lim y K. B. Mathur, «Modeling of particle movement in spouted beds», en Fluidization, J. F. Davidson y D. L. Keairns, Eds. Cambridge: Cambridge University press, 1978, pp. 104-109.

[22] N. Epstein y J. R. Grace, «Spouting of Particulate Solids», en Handbook of Powder Science \& Technology, M. E. Fayed y L. Otten, Eds. New York: Van Nostrand Reinhold, 1984, pp. 507-536.

[23] G. A. Lefroy, "The Mechanics of Spouted Beds. Tesis para la University of Cambridge», PhD Tesis, University of Cambridge, Cambridge, 1966.

[24] G. A. Lefroy y J. F. Davidson, «Mechanics of the spouted beds», Trans Inst Chem Eng, vol. 47, n. ${ }^{\circ}$ 5, pp. t120-t128, 1969.

[25] R. G. Szafran y A. Kmiec, «CFD Modeling of Heat and Mass Transfer in a Spouted Bed Dryer», Ind. Eng. Chem. Res., vol. 43, n. ${ }^{\circ}$ 4, pp. 1113-1124, feb. 2004. 